OPEN ACCESS

Edited by:

Angel Borja,

Technological Center Expert in Marine and Food Innovation (AZTI), Spain

Reviewed by:

Mario Barletta,

Federal University of Pernambuco,

Brazi

James G. Sanders,

University of Georgia, United States

*Correspondence: Rosa M. Fernández Otero rfernandez@cetmar.org

Specialty section:

This article was submitted to Marine Ecosystem Ecology, a section of the journal

Frontiers in Marine Science

Received: 05 January 2019

Accepted: 02 October 2019

Published: 18 October 2019

Citation:

Fernández Otero RM

Bayliss-Brown GA and Papathanassiou M (2019) Ocean Literacy and Knowledge Transfer

Synergies in Support of a Sustainable Blue Economy. Front. Mar. Sci. 6:646. doi: 10.3389/fmars.2019.00646

\section{Ocean Literacy and Knowledge Transfer Synergies in Support of a Sustainable Blue Economy}

\author{
Rosa M. Fernández Otero ${ }^{1 \star}$, Georgia A. Bayliss-Brown ${ }^{2}$ and Martha Papathanassiou ${ }^{3}$ \\ ${ }^{1}$ Centro Tecnológico del Mar, Fundación CETMAR, Vigo, Spain, ${ }^{2}$ AquaTT, Dublin, Ireland, ${ }^{3}$ Indigo-Med, Athens, Greece
}

Since 2011, when the first European ocean literacy (OL) project was launched in Portugal, the number of initiatives about this topic in Europe has increased notoriously and their scope has largely widened. These initiatives have drawn from the seven "OL Principles" that were developed by the College of Exploration OL Network in 2005. They represent a source of inspiration for the many endeavors that are aiming to achieve a society that fully understands the influence of themselves - as individuals and as a population - on the ocean and the influence of the ocean on them. OL initiatives throughout the past years, globally, have resulted in the production of countless didactic and communication resources that represent a valuable legacy for new activities. The OL research community recognizes the need to build up the scope of OL by reaching the wider Blue Economy actors such as the maritime industrial sector. It is hoped that building $\mathrm{OL}$ in this sector will contribute to the long-term sustainable development of maritime activities. The ERASMUS+ project "MATES" aims to address the maritime industries' skills shortages and contribute to a more resilient labor market. MATES' hypothesis is that through building OL in educational, professional and industrial environments, it is possible to build a labor force that matches the skills demand in these sectors and increases their capacity to uptake new knowledge. The MATES partnership will explicitly combine OL and knowledge transfer by applying the "COLUMBUS Knowledge Transfer Methodology" as developed by the H2020-funded COLUMBUS project.

Keywords: blue economy, knowledge management, ocean literacy, skills, stakeholder engagement, knowledge transfer, education

\section{SUGGESTING THE LINKS BETWEEN OCEAN LITERACY AND KNOWLEDGE TRANSFER}

The ocean represents $71 \%$ of the Earth's surface and it drives many features of life on Earth. The ocean makes the planet habitable and it hosts a vast majority of the living organisms. It regulates climate and it is a major source of water, nutrients, chemicals and oxygen (Valdés et al., 2017).

Human beings have an extremely complex, interconnected and inseparable relationship with the ocean. The ocean is crucial for man-kinds' wellbeing as it provides a vast quantity and diversity of services, such as health, food, transport, discovery, culture and inspiration. These factors broadly explain the importance of the ocean for humans and inspire the "Ocean Literacy (OL) Principles" 
(The Ocean Literacy Network, 2005). However, ocean health is seriously threatened, as it is forced to bear multiple anthropogenic pressures and is exposed to unsustainable practices such as overfishing and pollution. The cumulative effects of these drivers are causing biodiversity loss and habitat destruction; changes in biogeochemical and physical processes (such as ocean acidification); and, global warming, thus, contributing to climate change (Baker et al., 2019). There is a need to broadly acknowledge this situation, understand its consequences and take action at all levels - at land and sea - to achieve a sustainable existence of life on Earth, also manifested in the adoption of the United Nations Sustainable Development Goals, (SDGs) which call for action by all countries to promote prosperity while protecting the environment. In this discussion, SDG14 comes into play, with the particularly relevant Target 14.a. International ocean science cooperation is essential to increase scientific knowledge, develop research capacity and transfer marine technology (United Nations General Assembly, 2015). Ocean science is also critical to inform a range of international legal and policy developments concerning, for example, climate change and the conservation and sustainable use of marine biodiversity in areas within and beyond national jurisdiction; or the achievement of the Good Environmental Status in the EU marine waters by 2020 as proclaimed objective of the Marine Strategy Framework Directive. ${ }^{1}$

Developed over a decade ago, the seven OL Principles represent a source of inspiration for those working toward achieving an ocean literate society; one formed by individuals that fully understand the influence they have on the ocean and the influence the ocean has on them (Cava et al., 2005). The seven OL Principles are:

1. The Earth has one big ocean with many features.

2. The ocean and life in the ocean shape the features of Earth.

3. The ocean is a major influence on weather and climate.

4. The ocean made the Earth habitable.

5. The ocean supports a great diversity of life and ecosystems.

6. The ocean and humans are inextricably interconnected.

7. The ocean is largely unexplored.

The OL movement has developed a framework for the introduction of ocean science in schools' curricula and it has produced countless didactic and communication materials which represent a valuable legacy for future activities (Intergovernmental Oceanographic Commission - Unesco, 2018). It is expected that, as a result of the efforts to promote the inclusion of ocean sciences at all levels in education, younger generations will be the first in developing more sustainable behavioral patterns, and that their actions and convictions will instill a society-wide culture change. As distinctly mentioned in the OL for All: A Toolkit, in the future "OL will embrace all subjects, not only science, but also art, music, archeology, culture, geography, and [it is hoped] that definitions, principles

\footnotetext{
${ }^{1}$ Directive 2008/56/EC of the European Parliament and of the Council of 17 June 2008 establishing a framework for community action in the field of marine environmental policy (Marine Strategy Framework Directive).
}

and concepts will be adapted and developed to make it relevant locally" (Santoro et al., 2017). Therefore, there is potential to expand further the OL legacy beyond the educational sphere. It could reach other facets of citizens' lives such as its adoption in professional careers and industrial activities in different sectors, including those directly connected with the Blue Economy (World Bank and United Nations Department of Economic and Social Affairs, 2017; Realdon et al., 2018). In fact, ocean literate marine and maritime stakeholders would be expected to understand and acknowledge that ocean productivity and carrying capacity are finite, and therefore, they would be able to make more realistic projections about the scenarios for Blue Growth (Uyarra and Borja, 2016). The urgency of action needed to restore the ocean to a healthier status makes it necessary to take full advantage of all the existing resources and knowledge available. The challenge is in communicating these messages and stimulating the knowledge uptake and action from a vast range of stakeholders including scientists, entrepreneurs, educators, politicians, professionals and citizens in general.

Based on a recent review of OL in EU maritime policy, conducted in the framework of the H2020-funded Sea Change Project, it was concluded that "EU maritime policy is largely based on the concept of $O L$, evidenced by reference to the OL principles and fundamental concepts either in the policy text itself or in associated communication products. This is although the term "OL" is not used in the policies. An exception is the use of the term in the 2013 Galway Statement on Atlantic Ocean Cooperation which builds on the Atlantic Action Plan as part of the Blue Growth Strategy." (French et al., 2015).

For the OL movement to be truly transformative, all voices and all subjects need to be included. In this framework, the UNESCOIOC initiative, which was launched in 2017, could provide a "voice" for a global OL movement, which extends beyond borders and nations and reaches out to the farthest countries that depend on the ocean and its resources. The "OL for all: a global strategy to raise the awareness for the conservation, restoration, and sustainable use of our ocean" initiative will encourage wider participation in the future of OL, including the engagement of individuals from different sectors of society.

Already existing worldwide initiatives that we can look at include the H2020-funded Atlantic Ocean Research Alliance (AORA), which coordinates marine science educators in Europe, the United States and Canada to better inform and engage citizens about the ocean's influence on them and their influence on the ocean. Through AORA, for the first time, there is now a transatlantic strategy on OL. The Transatlantic Implementation Strategy (TIS) drafted under AORA (Atlantic Ocean Researcg Aliance Marine Working Group Ocean Literacy, 2016), aims to consolidate existing efforts toward a proof of concept for Transatlantic Ocean Literacy (TOL).

\section{COLUMBUS}

The Horizon 2020 funded project, COLUMBUS ${ }^{2}$, developed the COLUMBUS Knowledge Transfer Methodology (AquaTT, 2015a).

${ }^{2}$ COLUMBUS project received funding from the European Union's Horizon 2020 Research and Innovation Programme under grant agreement no. 652690. 
Through 48 case studies, it has demonstrated its applicability for transferring knowledge from science to science, policy, society and industry in any sector and location (COLUMBUS partnership, 2018b). A unique aspect of knowledge transfer - that differentiates it from regular dissemination activities - is that it identifies an individual stakeholder's needs and plans its communication activities to suit this target's profile; thus, better ensuring the knowledge uptake and the generation of an impact. This targeted activity considers the individual's needs, mandate, technical background, preferences, and their circles of influence and concern. Hence, allowing a broader range of stakeholders to be engaged and action stimulated within them.

\section{MATES}

A newly funded project, the ERASMUS+ Blueprint for a Sector Skills' Alliance in the maritime technologies, MATES, is attempting to synergize knowledge transfer and OL to improve the maritime sectors' image and performance (I-Tech AB-Selektop, 2018; Mates partnership, 2018). MATES will be using targeted communication techniques to develop OL across a range of stakeholder groups and increasing the capacity of the industry to perform their activities sustainably, thanks to a more proactive knowledge uptake. Maritime stakeholders, including present and future employers and employees who are ocean literate, are expected to be willing to adopt more sustainable knowledge and technologies. The hypothesis being that more intense and efficient adoption of new knowledge and technologies offering more sustainable practices will have a positive effect on a sector's image and on the marine environment.

This article will present practical experiences - some of which were carried out within COLUMBUS - that illustrate a mutual benefit between OL and knowledge transfer. It also proposes how present and future OL activities - such as the current efforts in the context of the ERASMUS + MATES project - could build upon the rationale of COLUMBUS, reaching alternative audiences under a systematic approach.

\section{THE COLUMBUS PROJECT AS A FLAGSHIP KNOWLEDGE TRANSFER INITIATIVE FOR THE BLUE ECONOMY}

In 2012, the European Commission published the Blue Growth Agenda (European Commission, 2012) and, in 2014, released its communication relating to the Blue Economy and the need to realize the innovation potential of our seas and oceans for jobs and growth (European Commission, 2014). Both communications acknowledged the capacity of the marine and maritime activities to generate growth and employment on a sustainable basis and the need to boost innovation and knowledge transfer as a requirement to underpin such potential and guarantee sustainability. Europe's Marine Economy is not an exception comparing its situation with the whole innovation system within the EU, as far as similar weaknesses are observed: under-investment in knowledge; poor access to finance; the high cost of intellectual property rights; slow progress toward interoperable standards; ineffective use of public procurement and duplications in research; insufficient collaboration between the public and private sectors on innovation; poor transfer of research results into goods and services; and, a growing skills' gap (European Economic Social Committee [EESC], 2014).

In this context, the COLUMBUS project aimed at "ensuring that applicable knowledge generated through EC-funded science and technology can be transferred effectively to advance the governance of the marine and maritime sectors while improving competitiveness of European companies and unlocking the potential of the oceans to create jobs and economic growth in Europe on a sustainable (Blue Growth)" (AquaTT, 2015b).

Knowledge transfer was defined by COLUMBUS as "the term for the overall process of moving knowledge between knowledge sources to targeted potential users of knowledge. Knowledge transfer consists of a range of activities which aim to capture, organize, assess and transmit knowledge, skills and competence from those who generate them to those who will utilize them." This definition builds upon and synthesizes previous definitions, around the same concept. Most coincide in the requirement that the knowledge effectively moves from those who generate it to those who can effectively adopt and apply it. Transferrable knowledge can be found in a variety of formats and natures ranging from tangible intellectual property, products or patents to skills, know-how and expertise (Minshall, 2009). Knowledge transfer can involve a wide range of activities.

Knowledge transfer, as well as OL, always involves communication between individuals. For this to be effective and efficient, there is a need to properly understand the motivations of those who shall participate in the process, what the message(s) should be, how to transmit it (them), and through which means and when. Furthermore, actions for guaranteeing impact generation, as well as suitable mechanisms to measure this impact must be well planned and implemented.

The "COLUMBUS Knowledge Transfer Methodology" was designed to target any individual and so it can be applied to any individual irrespective of where they come from; any country or background, from industry, governance and policy spheres, from science, from education or from any other societal group. Whilst it was designed for the marine sector, it can be applied in any sector (although both COLUMBUS and MATES initiatives have the condition to respond to demands directly connected to the European Blue Economy) but it needs a good understanding of the context for application.

Three key concepts were defined as part of the COLUMBUS Methodology:

- Knowledge Output: A unit of knowledge or learning generated by or through research activity. They are not limited to de novo or pioneering discoveries but may also include new methodologies/processes, adaptations, insights, alternative applications of prior know-how/knowledge.

- Knowledge Output Pathway: A single step or a series of steps that are required to carry a Knowledge Output to its 
Eventual Impact. It can include detailed mapping of the steps, the users involved at each step and their predicted role in the pathway to Eventual Impact.

- Eventual Impact: The ultimate end benefit of the application of the Knowledge Output. It is defined as an enhanced situation that is contributing to a political, industrial, scientific or societal need.

According to these definitions, COLUMBUS focused its efforts on collecting explicit units of knowledge (Koulopoulos and Frappaolo, 1999) which in the terminology of the project were named as Knowledge Outputs. These are articulated in lay terms to allow them to be transferred from any individual to another regardless of sector or background.

To explain the process that occurred, the European marine and maritime legislation was reviewed and combined with challenges identified by industry to describe key knowledge needs for nine groups of marine activities. Keywords from these identified knowledge needs were used to search the Marine Knowledge Gate (EurOcean, 2018) - a database containing information about national and European Commission-funded marine and maritime projects - as it was assumed that project abstracts containing these words might offer a solution to the identified sectoral needs. The selected projects were then reviewed for relevance to the sector. Knowledge was then collected from all of the projects deemed as most relevant and most likely to have performed research that might contribute to a solution for a sectoral need. The Knowledge Outputs that were determined to be relevant to the knowledge needs progressed to the "analysis" phase. Every Knowledge Output was analyzed: their application landscapes mapped, and target users identified. Where the analysis showed that there was a high potential for the application of the Knowledge Outputs to fulfill a knowledge gap, the Knowledge Output was transferred to the target user.

COLUMBUS was able to identify 967 projects which may have produced solutions that responded to the needs of nine marine and maritime activities. A total of 1,779 Knowledge Outputs were collected from these projects. Of these, 246 were prioritized and 56 knowledge transfer activities were completed. 48 of these success stories were released for public dissemination (COLUMBUS partnership, 2018b). The systematic approach followed by COLUMBUS can supplement the efforts of the OL community to reach new targets and levels of impact. To achieve OL and provoke a change in behavior - as observed in the COLUMBUS Knowledge Transfer Methodology - and to stimulate OL, the key messages, transmission channels and target audiences should be selected according to the specific pursued impact. Accordingly, OL can be considered a specific result of knowledge transfer, "science-to-all-society."

OL impact measurement was recently comprehensively studied during the development of an International OL Survey, which considers the broad scope of OL actions and stakeholders (Fauville et al., 2018b). Education, a community commonly approached by OL practitioners, represents a traditional pathway for knowledge transfer. Without evaluation, it is difficult to understand if knowledge from research activity has been taken up and applied by students (Jenkins and Zetter, 2003). The development of standardized methods to track and measure impact is, therefore, relevant and opportune. A systematic approach to achieve impact from knowledge transfer and OL processes can be of mutual benefit for efforts in both directions. Education and training communities and Blue Economy stakeholders can benefit from a combined approach and the MATES consortium will explore this further.

\section{OCEAN LITERACY AND THE BLUE ECONOMY}

There are several examples that can be drawn upon that illustrate the influence that OL can have on the wider society, with the Blue Economy stakeholders making up a key part of it.

In the past decade, United Kingdom citizens have seen that their actions can lead to policy change. TV chef Hugh FearnleyWhittingst all launched the Fish Fight campaign to end discards in 2010. More than 870,000 individuals from 195 countries joined the campaign and 3 years later, European politicians voted to ban discards (Hugh Fearnley-Whittingstall, 2014). More recently, Surfer's against Sewage's Plastic-Free Parliament's campaign and Plastic Free Communities campaign were discussed in Parliament. These actions will contribute to a reduction of avoidable plastic packaging in supermarkets (Surfers Against Sewage, 2018). Films such as Sharkwater, Blackfish and The Cove are also a medium that is shown to influence policy.

Industries are also seen to be adapting their modus operandi by developing sustainability programs or embracing the circular economy. The Volvo Ocean Race, an internationally recognized sports event, was awarded the Sports CSR Campaign of the year at the International Sports Awards (Clegg, 2018). This award was given to celebrate Volvo Ocean Race's powerful message around marine plastics which influenced changes to business models and government policy as a direct result of the race. Clothing companies are increasingly using recycled waste found in oceans and rivers to produce yarn and some are even using algae for the outer sole of shoes (Carter, 2018). A football kit made from recycled ocean plastic has even been created for Manchester United Football Club by Adidas, and the sportswear brand has committed to using recycled plastic in all its products by 2024 (Hitti, 2018).

The large amount of experiences around marine litter (research, awareness, education, innovation experiences, etc.) in different domains and contexts (industrial, societal, public policies, etc.) could be considered to represent a relevant window of opportunity to systematize knowledge transfer and to exploit available Knowledge Outputs, including those for OL and general awareness. COLUMBUS also made some preliminary steps forward in this regard where Knowledge Outputs from the two $\mathrm{FP7}^{3}$ projects MARLISCO (Marlisco Consortium, 2015) and CLEANSEA (Cleansea Consortium, 2015) were transferred by ${ }^{3}$ The European Union's Seventh Framework Program for Research and
Technological Development (2007-2013). 
one COLUMBUS partner, JÜLICH ${ }^{4}$. The first activity supported the formal adoption of marine litter related education units by teachers in public education centers in Germany. The second aided the design and development of local campaigns against ghost fishing gear in two United Kingdom localities (COLUMBUS partnership, 2018b). Another COLUMBUS partner, CETMAR, released a dossier compiling and classifying relevant past marine litter projects and outputs, making this information more easily accessible for future transfer and exploitation and supporting the follow up of the topic by the EC-JRC $^{5}$, who suggested the convenience of such a report (Fundación Cetmar, 2017).

The Horizon 2020 funded project ResponSEAble developed some OL products (Responseable consortium, 2018) built on the idea that environment-friendly practices and the adoption of available knowledge could lead to more competitive maritime industries, with a better image of their business. This idea was evoked by similar OL products developed for sustainable aquaculture and invasive alien species, among others. These and other examples that follow this approach will be gathered and used for inspiration in the new project, MATES.

The developers of new coatings and anti-fouling solutions, identified by COLUMBUS as promising transferrable Knowledge Outputs from EU funded research, were invited to a brokerage event in Brussels, organized by partners ECMAR ${ }^{6}$, Aquatera ${ }^{7}$, and $\mathrm{CMT}^{8}$ (COLUMBUS partnership, 2018a). The Knowledge Outputs presented comprised different coatings and coating ingredients that can be used by the maritime industries to avoid damage caused by the attachment of marine organisms to vessels' hulls and marine devices such as offshore renewable installations or marine observation buoys. During the brokerage event, the antifouling properties of the different solutions were presented along with the results of preliminary field trials for some of the products. Many topics surrounding the sector were also discussed, such as the mechanisms used by some of the marine organisms to attach to the different types of surfaces; why the antifouling solutions should be achieved at no environmental cost; the environmental advantages to using an antifouling solution derived for more efficient energy performance. Although no fit for all purposes solution is yet available, the event followed to promote the interaction between scientists and industrials allowed the latter to more easily follow up the evolution of promising technologies and the opportunities to apply them to different markets; to acknowledge and understand the importance of environmental-friendly solutions; and, to be ready to collaborate to speed up the uptake of knowledge (COLUMBUS partnership, 2018b).

These examples show that OL has and will continue to have a significant impact on behavioral change in society, and when combined with knowledge transfer strategies, it contributes to a better predisposition of the knowledge users

\footnotetext{
${ }^{4}$ PROJEKTTRÄGER JÜLICH.

${ }^{5}$ European Commission Joint Research Centre.

${ }^{6}$ European Council for Maritime Applied R\&D.

${ }^{7}$ Aquatera.

${ }^{8}$ Center of Maritime Technologies.
}

of all kinds, including industry, to uptake the best available, sustainable knowledge from research and innovation efforts. The MATES project will combine the practical approach developed by COLUMBUS for knowledge transfer activities with the most recent guiding principles and protocols for the implementation of OL activities emanating from the Horizon 2020 Sea Change project (McHugh et al., 2015). MATES will particularly explore those that can more easily aid connecting and interacting with the maritime industries and embedding and involving all the relevant stakeholders in the process, following the recommendations and expectations about the future of OL by IOC-UNESCO (Santin et al., 2017).

Compiling and organizing information about past practices will allow the extraction of lessons from the past. This is crucial to avoid duplication of efforts and inefficient use of resources. The MATES project represents an important opportunity to put the lessons learnt from the past and recommendations into practice, and to do it in a context which has not been fully explored in so far: A context derived from the mismatch between skills demands and training offers for the maritime activities; in particular, the shipbuilding and the off-shore renewable energy value chains.

This new project was designed to take advantage of the potential for synergies between knowledge transfer and OL as described in this article and to overcome some of the barriers for more successful achievements. As well as raising awareness about the relevance of the ocean to the maritime community, MATES will develop the "Skilling Strategy" for the maritime technologies' sectors in Europe addressing all education levels with a special emphasis on Vocational Education and Training (VET). Accordingly, it is hoped that MATES will result in a better predisposition of maritime employers to uptake an ocean literate labor force for improving the sustainability of their business performance and enhancing the sectors' image and competitiveness.

\section{DIFFICULTIES FOR OL AND KT IMPLEMENTATION AND FUTURE CHALLENGES}

Beyond synergies, there are also many barriers to knowledge transfer and some many coincide or have quite evident connections with those hampering the raise of the levels of OL in society, particularly in the industry. The OL community has comprehensively mapped the barriers for teaching Europe's young students about the ocean and has also gained an understanding of how these barriers are interlinked, including those that connect ocean education efforts and the Blue Economy, through marine careers and industry (Fauville et al., 2018a).

The FP7 funded project MarineTT (AquaTT, 2015c) ranked the barriers to knowledge transfer and innovation from marine research in Europe. These were later presented alongside a full review of challenges, opportunities and recommendations relating to outreach and dissemination (Reuver et al., 2016). From the works cited and from the further experience gained in projects like COLUMBUS and MATES, it is possible to identify 
some outstanding commonalities expressed in terms of shared shortcomings which point at relevant fields for future actions:

- There is insufficient awareness about the importance of the ocean for humanity in general, particularly for economic activities.

- Accessibility to knowledge has dramatically improved with Open Access policies, but access is not enough for the knowledge to reach out the wider community of potential users of the knowledge available. Ocean literate users will be prone to identify and uptake best available knowledge.

- There is a general lack of understanding on how to systematically and complementarily carry out knowledge transfer and OL actions, especially when the industry is targeted. Complementary approaches as proposed by MATES should be further explored.

- The basic concepts and the specific lexicon used to refer to OL, knowledge transfer and science communication are commonly mixed up and used on a loose basis. Sometimes a specific term becomes best-selling and this frequently leads to misuse or overuse of such terms while other relevant ones are abandoned (Uyarra and Borja, 2016).

- The connections between stakeholders and practitioners from the different spheres or sectors - science, education, industry, policy, and the wider citizenship - are yet insufficient. It is difficult to break the work-in-silos culture. Long-term multi-stakeholder initiatives should be further promoted.

- Motivations and potential incentives of and for the different stakeholder groups are different and not always fully known and acknowledged from one group to another. Analysis is needed for efficient approaches to knowledge transfer and OL.

- Impact generation and measurement is essential for both knowledge transfer and OL efforts. However, there are limited or no repercussions for projects that are not achieving their expected impacts, and most commonly their socio-economic targets.

- Knowledge transfer and OL activities need a strategic and systematic approach for their implementation and thus, they need to be planned, monitored and evaluated once executed.

- Knowledge transfer and OL require skills, time and resources. There is insufficient investment on knowledge transfer, communication and/or OL activities. These activities are often considered secondary components of the research life-cycle, at least when the resources for their implementation are assigned.

\section{CONCLUSION ABOUT THE SYNERGIES BETWEEN OCEAN LITERACY AND KNOWLEDGE TRANSFER}

The most common playing field for the OL movement in Europe, so far, has been within the education sector and the general public. In fact, the work done by OL practitioners has connected research and education and translated some of the best available marine knowledge into didactic contents, comprehensive for students and trainees of all ages. OL, as well as marine knowledge transfer, represents a specific service application of marine knowledge management and its potential to have an impact on the sustainable development of the marine economic activities, whilst already broadly recognized (Santoro et al., 2017), needs to be further developed.

Recent efforts in marine and maritime knowledge transfer and OL have provided a more systematic approach for both types of activities, facilitating the understanding of the required steps by any practitioner (AquaTT, 2015a; McHugh et al., 2015; Fauville et al., 2018b). They have also enabled the exploitation of potential synergies, especially in reaching the Blue Economy stakeholders' communities. OL and knowledge transfer services can be combined to provide a permanent route for state-of-theart marine science to be delivered through a diversity of means and formats (seminars, workshops, conferences, social media, massive online courses, etc.) to these stakeholders (Amaratunga and Senaratne, 2008). It is, therefore, assumable that good practices and insights in marine and maritime knowledge transfer can benefit future OL efforts and, vice versa, materials and lessons learnt from past experiences can be shared between the two communities of practitioners.

The quality of the answers of individuals about a given matter is directly related to the amount and quality of knowledge they hold about such a matter. Increased education and skills development surrounding the ocean and the knowledge transfer practices (a) supports the synthesis of relevant knowledge, which is essential for a better understanding and for making informed decisions; (b) allows for creativity and innovation and for the development of the so-called "21st Century Skills" (Partnership for 21st Century Skills, 2015); and, (c) unveils for all, the valuable services from the marine environment. Thus, through developing OL in Blue Economy stakeholders and through the systematization of marine knowledge transfer, the environmental performance of marine and maritime sectors is expected to improve. The enhancement of the maritime sectors' image will come as a consequence.

The MATES project represents an important opportunity to put the lessons learnt from the past and these recommendations into practice. This new project is designed to take advantage of the potential for synergies between knowledge transfer and OL practices and practitioners as described in this article, and to overcome some of the barriers for more successful achievements. The integration of $\mathrm{OL}$ aspects as a horizontal component of the MATES' strategy design, will allow for the identification of most suitable pathways and action lines for an eventual impact consisting in a better predisposition of maritime employers to uptake an ocean literate labor-force and stateof-the-art marine knowledge and ultimately, to enhance the maritime sectors' image. MATES has foreseen specific efforts for the roll out of the resulting strategy beyond the project execution and at different geographic levels (EU, Member States and Regions). The strategy implementation will be addressed with the involvement of multiple stakeholders: from the industry, from the education and academia sectors and from the administrations. 
The MATES partnership is already a multi-stakeholder network committed to undertake the Strategy and to scale up successful pilot experiences. This legacy will be promoted toward the wider marine and maritime communities, especially, at EU level. Achievements, however, will have a broader effect because MATES' partners as well as, in general, the EU maritime stakeholders are strongly interconnected at global scale.

\section{AUTHOR CONTRIBUTIONS}

All authors listed have made a substantial, direct and intellectual contribution to the work, and approved it for publication.

\section{FUNDING}

This work was co-funded by the Erasmus+ Program of the European Union through the Sector Skills Alliance project "MATES - Maritime Alliance for fostering the European Blue

\section{REFERENCES}

Amaratunga, D., and Senaratne, S. (2008). A Knowledge Transfer Perspective on Research and Teaching in Higher Education. Manchester: University of Salford.

AquaTT (2015a). Deliverable 2.2. Guidelines on Carrying out COLUMBUS Knowledge Transfer and Impact Measurement. Columbus Website - Results. Available at: http://www.columbusproject.eu/D2\%202\%20Guidelines\%20on\% 20carrying\%20out\%20COLUMBUS\%20KT\%20v2\%20Final\%2030.11.15.pdf (accessed October 09, 2019).

AquaTT (2015b). H2020 Project COLUMBUS, Description of Action. Ireland: AquaTT (accessed October 09, 2019).

AquaTT (2015c). MarineTT Project Website. Deliverable 4.4. Handbook on Marine TT: European Marine Research Knowledge Transfer and Uptake of Results. Available at: http://marinett.eu/images/MARINETT/materials/D\%204. 4\%20Handbooks.pdf (accessed October 09, 2019).

Atlantic Ocean Researcg Aliance Marine Working Group Ocean Literacy (2016). Transatlantic Implementation Strategy (TIS). Available at: https: //www.atlanticresource.org/aora/sites/default/files/GalleryFiles/Publications/ TransAtlanticOceanLiteracyImplementationStrategy22Jan2016.pdf (accessed October 09, 2019).

Baker, E., Harris, P., Mangalagiu, D., Fidelman, P., Gonçalves, L. R., Hollway, J., et al. (2019). Global Environment Outlook (GEO6) Chapter 7: Oceans and coasts. Cambridge University Press: Cambridge, MA

Carter, T. (2018). Dezeen.Com. Ecoalf Unveils Shao Sneakers Made From Algae and Ocean Plastic. Available at: https://www.dezeen.com/2018/07/15/ecoalf-shaosneakers-algae-ocean-plastic-waste/ (accessed October 09, 2019).

Cava, F., Schoedinger, S., Strang, C., and Tuddenham, P. (2005). Science Content and Standards for Ocean Literacy: A Report. 2005. Available at: http://www. cosee.net/files/coseeca/OLit04-05FinalReport.pdf (accessed October 09, 2019).

Cleansea Consortium, (2015). Cleansea Project Website. Towards a Clean, LitterFree European Marine Environment through Scientific Evidence, Innovative Tools and Good Governance. Available at: https://cleanseaproject.wordpress. com/ (accessed October 09, 2019).

Clegg, R. (2018). Global Leader in Sport and Sustainability. Available at: https://www.volvooceanrace.com/en/news/12207_Global-leader-in-sportand-sustainability.html (accessed October 09, 2019).

COLUMBUS partnership (2018a). COLUMBUS Results - Columbus Brokerage Events. Available at: http://www.columbusproject.eu/ COLUMBUSBrokerageEvents.pdf (accessed October 09, 2019).

COLUMBUS partnership (2018b). COLUMBUS Stories of Marine and Maritime Knowledge Transfer Activities. Available at: http://www.columbusproject.eu/ CCV6_FINAL.pdf (accessed October 09, 2019).
Economy through a Marine Technology Skilling Strategy (Ref. 2017-3114/001-001)" The European Commission support for the production of this publication does not constitute an endorsement of the contents which reflects the views only of the authors, and the Commission cannot be held responsible for any use which may be made of the information contained therein.

\section{ACKNOWLEDGMENTS}

We would like to express our gratitude to the COLUMBUS partnership and very especially to the network of Knowledge Fellows for their insights about the knowledge transfer methodology implementation. We would also like to thank the MATES partnership for their support to give continuity to previous works and explore new possibilities and approaches around the connections between knowledge transfer in the maritime sectors and ocean literacy concepts.

EurOcean, (2018). EurOcean Marine Knowledge Gate 2.0. Available at: http://www. kg2.eurocean.org/ (accessed December 12, 2018).

European Commission, (2012). Communication from the Commission to the European Parliament, The Council, The European Economic and Social Committee, and The Committee of the Regions: Blue Growth Opportunities for Marine and Maritime Sustainable Growth. Brussels: European Commission.

European Commission, (2014). Communication from the Commission to the European Parliament, the Council, the European Economic and Social Committee and the Committee of the Regions - Innovation in the Blue Economy: Realising the Potential of Our Seas and Oceans for Jobs and Growth. Brussels: European Commission.

European Economic Social Committee [EESC] (2014). Opinion of the EESC on the Innovation in the Blue Economy: Realising the Potential of our Seas and Oceans for Jobs and Growth. Brussels: European Economic Social Committee.

Fauville, G., McHugh, P., Domegan, C., Mäkitalo, Å, Friis Møller, L., Papathanassiou, M., et al. (2018a). Using collective intelligence to identify barriers to teaching 12-19 year olds about the ocean in Europe. Mar. Policy 91, 85-96. doi: 10.1016/j.marpol.2018.01.034

Fauville, G., Strang, C., Cannady, M. A., and Chen, Y. F. (2018b). Development of the international ocean literacy survey: measuring knowledge across the world. Environ. Educ. Res. 25, 238-263. doi: 10.1080/13504622.2018.1440381

French, V., Chu, N. C., Santoro, F., Sousa Pinto, I., Borges, D., and McDonough, N. (2015). Review of Ocean Literacy in European Maritime Policy. Sea Change. One Ocean, One Health. Available at: https://www.seachangeproject.eu/images/SEACHANGE/SC_Results//D5. 1Review_of_Ocean_Literacy_in_Governance.pdf (accessed October 09, 2019).

Fundación Cetmar, (2017). COLUMBUS Project Website. Section: Results. Relevant knowledge Gathered in the Framework of COLUMBUS Project to Address MSFD - Descriptor 10: Marine Litter. Available at: http://www.columbusproject. eu/Annex1.COLUMBUS_MARINE\%20LITTER\%20DOSSIER.PDF (accessed October 09, 2019).

Hitti, N. (2018). Dezeen.com. Adidas Reveals Manchester United Kit Made From Ocean Plastic. Available at: https://www.dezeen.com/2018/05/18/adidasreveals-latest-manchester-united-kit-made-from-parley-ocean-plastic/ (accessed October 09, 2019).

Hugh Fearnley-Whittingstall (2014). Fish Fight. Available at: https://www. rivercottage.net/campaigns/hughs-fish-fight

Intergovernmental Oceanographic Commission - Unesco (2018). Ocean Literacy Portal. IOC-UNESCO. Available at: https://oceanliteracy.unesco.org/ (accessed October 09, 2019).

I-Tech AB-Selektop (2018). Selektop Website. Selektope Success In: A Review of the Year 2018. Available at: https://selektope.com/category/press-releases/ (accessed October 09, 2019). 
Jenkins, A., and Zetter, R. (2003). Linking Research and Teaching in Departments. New York, NY: Oxford Brookes University.

Koulopoulos, T., and Frappaolo, C. (1999). Smart Things to Know About Knowledge Management. New Hampshire: Dover.

Marlisco Consortium, (2015). MARLISCO Project Website. Marine Litter in European Seas - Social Awareness and Co-Responsibility. Available at: http: //www.marlisco.eu/about-project.en.html (accessed October 09, 2019).

Mates partnership, (2018). MATES - Maritime Alliance for fostering the European Blue Economy through a Marine Technology Skilling Strategy. ERASMUS+ - Sector Skills Alliances. Available at: https://www.projectmates.eu/ (accessed October 09, 2019).

McHugh, P., Domegan, C., Devaney, M., and Hastings, G. (2015). A set of Sea Change Ocean Literacy Guiding Principles. Sea Change Project Website. Available at: http://www.seachangeproject.eu/images/SEACHANGE/ SC_Results//Deliverable-D.2.2.pdf (accessed October 09, 2019).

Minshall, T. (2009). Center for Technology Management, Cambridge Institute For Manufacturing. What is knowledge transfer? Cambridge, MA: University of Cambridge.

Partnership for 21st Century Skills (2015). P21 Framework Definitions Document. Available at: https://files.eric.ed.gov/fulltext/ED519462.pdf (accessed October 09, 2019).

Realdon, G., Candussio, G., Fabris, S., and Rossi, M. P. (2018). "Promoting Ocean Literacy (OL) by means of a partnership between two stakeholders," in Proceedings of the 20th EGU General Assembly, EGU2018, Proceedings from the conference held 4-13 April, 2018, Vienna.

Responseable consortium (2018). ResponSEAble Project Website. Ocean Literacy Tools - For Professionals. Available at: https://www.responseable.eu/\#about (accessed October 09, 2019).

Reuver, M., Bayliss-Brown, G. A., Calis, T., Cardillo, P., NíCheallacháin, C., and Dornan, N. (2016). Outreach of the Unseen Majority. [book authors] L.J Stal y M.S. Cretoiu. The Marine Microbiome. An Untapped Source of Biodiversity and Biotechnological Potential. Berlin: Springer International Publishing.

Santin, S., Santoro, F., Fauville, G., and Scoucroft, G. (2017). Ocean Literacy for All: A Toolkit. France: United Nations Education, Science and Cultural Organization.
Santoro, F., Selvaggia, S., Gail, S., Géraldine, F., and Peter, T. (2017). Ocean Literacy for all: A Toolkit. Paris: UNESCO.

Surfers Against Sewage, (2018). Plastic-Free Fruit and Veg in ALL Supermarkets. Available at: https://www.sas.org.uk/uncategorised/plastic-free-fruit-and-vegin-all-supermarkets/ (accessed October 09, 2019).

The Ocean Literacy Network. (2005). Ocean Literacy: The Essential Principles of Ocean Sciences K-12. On-line Workshop on Ocean Literacy through Science Standards. Washington, D.C: National Geographic Society.

United Nations General Assembly (2015). UN Sustainable Development Goals2030 Agenda For Sustainable Development. Goal 14: Conserve and Sustainably use the Oceans, Seas and Marine Resources. Available at: https://www.un.org/ sustainabledevelopment/oceans/ (accessed October 09, 2019).

Uyarra, M. C., and Borja, A. (2016). Ocean literacy: a 'new' socio-ecological concept for a sustainable use of the seas. Berlin: Elsevier.

Valdés, L., Mees, J., and Enevoldsen, H. eds (2017). International Organizations Supporting Ocean Science Global Ocean Science Report - The current status of ocean science around the world. Paris: UNESCO Publishing.

World Bank, and United Nations Department of Economic, and Social Affairs, (2017). The Potential of the Blue Economy: Increasing Long-term Benefits of the Sustainable Use of Marine Resources for Small Island Developing States and Coastal Least Developed Countries. Washington, DC: World Bank.

Conflict of Interest: MP is founder and CEO of company Indigo-Med.

The remaining authors declare that the research was conducted in the absence of any commercial or financial relationships that could be construed as a potential conflict of interest.

Copyright (c) 2019 Fernández Otero, Bayliss-Brown and Papathanassiou. This is an open-access article distributed under the terms of the Creative Commons Attribution License (CC BY). The use, distribution or reproduction in other forums is permitted, provided the original author(s) and the copyright owner(s) are credited and that the original publication in this journal is cited, in accordance with accepted academic practice. No use, distribution or reproduction is permitted which does not comply with these terms. 